\title{
Application of Reference Voltage Control Method of the Generator Using a Neural Network in Variable Speed Synchronous Generation System of DC Distribution for Ships
}

\author{
Hyeonmin Jeon $₫$ and Jongsu Kim * \\ Department of Marine System Engineering, Korea Maritime and Ocean University, 727 Taejong-ro, Busan 49112, \\ Korea; jhm861104@kmou.ac.kr \\ * Correspondence: jongskim@kmou.ac.kr
}

Received: 3 September 2020; Accepted: 13 October 2020; Published: 15 October 2020

\begin{abstract}
In the case of DC power distribution-based variable speed engine synchronous generators, if the output reference voltage is kept constant regardless of the generator engine operating speed, it may cause damage to the internal device and windings of the generator due to over-flux or over-excitation. The purpose of this study is to adjust the generator reference voltage according to the engine speed change in the DC distribution system with the variable speed engine synchronous generator. A method of controlling the generator reference voltage according to the speed was applied by adjusting the value of the variable resistance input to the external terminal of the automatic voltage regulator using a neural network controller. The learning data of the neural network was measured through an experiment, and the input pattern was set as the rotational speed of the generator engine, and the output pattern was set as the input current of the potentiometer. Using the measured input/output pattern of the neural network, the error backpropagation learning algorithm was applied to derive the optimum connection weight to be applied to the controller. For the test, the variable speed operation range of the generator engine was set to $1100-1800 \mathrm{rpm}$, and the input current value of the potentiometer according to the speed increase or decrease within the operation range and the output of the voltage output from the actual generator were checked. As a result of neural network control, it was possible to confirm the result that the input current value of the potentiometer accurately reached the target value 4-20 mA at the point where the initial speed change occurred. It was confirmed that the reference voltage was also normally output in the target range of 250-440 V.
\end{abstract}

Keywords: DC distribution system; variable speed synchronous generator engine; reference voltage control; neural network controller

\section{Introduction}

\subsection{Background}

The emission of air pollutants from maritime vessels has been gradually increasing over time. According to the most recent statistics, as released annually by the National Institute of Environmental Research in South Korea, sulfur oxide discharged from maritime vessels accounts for $11.3 \%$ of the total air pollutants, whereas nitrogen oxide accounts for $13.0 \%$, and fine particulate matter account for $7.0 \%$. These pollutants are at a considerably larger emission scale than that from power generation facilities, manufacturing plants, and automobiles, which are recognized as a general source of air pollutant emissions [1,2]. In addition, according to the "Fourth IMO Greenhouse Gas Study 2020" conducted by the International Maritime Organization (IMO), the greenhouse gases generated from 
vessels from 2012 to 2018 accounted for an average of $2.5 \%$ of the total greenhouse gases generated from all industries [3].

To suppress the emissions from maritime vessels, the IMO, in its 70th session, established the "Prevention of Air Pollution from Ships" agreement in the form of an annex to the International Convention for the Prevention of Pollution from Ships, 1997 (MARPOL 73/78) and the Marine Environment Protection Committee (MEPC), to limit the sulfur content in fuel oil used for ship navigation to $0.5 \%$. In the 72 nd session, the MEPC adopted a strategy to achieve the greenhouse gas reduction target $[4,5]$. To promote the development and distribution of eco-friendly vessels, the South Korean government implemented the "Act on the Promotion of Development and Distribution of Environmentally Friendly Ships", which establishes and promotes comprehensive countermeasures and policies, with effect from 1 January 2020 [6].

\subsection{Current Issue}

Given the more stringent regulations as discussed in Section 1.1, the construction of "eco-friendly" electric propulsion ships is expected to gain momentum, as shown in Figure 1a,b. Figure 1a explains the increase in contracts for eco-friendly ships compared to global ship contracts, and Figure $1 \mathrm{~b}$ shows the expected results for the construction of electric ships in the future [7-9].

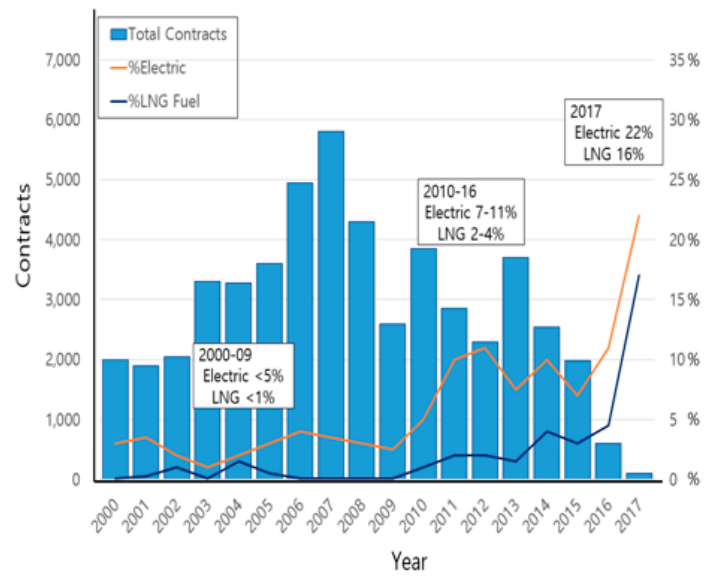

(a)

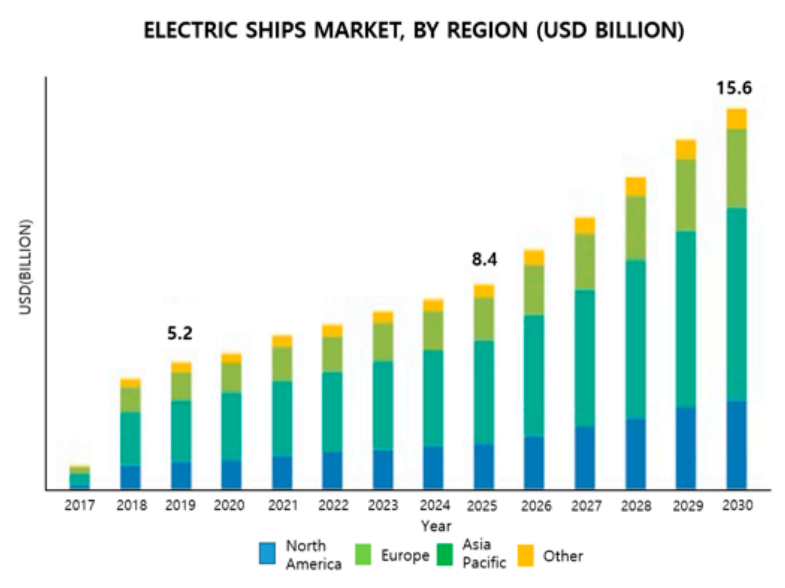

(b)

Figure 1. (a) Electric propulsion ship contract status and (b) market forecast (Clarkson Research, 2017; Market Research Report, 2019).

Most electric propulsion ships in operation are based on AC distribution systems. With the AC distribution system, the power quality of the entire ship may deteriorate due to a decrease in the stability of the automatic voltage regulator of the synchronous generator upon the occurrence of sudden load variations $[10,11]$. The most fundamental method for enhancing the stability of the generator in an AC distribution system is to improve the performance of proportional-integral-derivative (PID) controller of the automatic voltage regulator system [12-17]. There are various alternative methods such as the self-tuning of the PID controller gain with respect to the load variations [18] and the application of the stochastic fractal search algorithm to the PID controller, as is currently implemented [19]. Moreover, the application of a fuzzy-based control system [20-23] and a multilayer neural network [24-27] was proposed.

Given that the generator engine always operates at a fixed frequency irrespective of the actual load on the ship, fuel consumption increases during low-load operation, thereby increasing the emissions [28-30]. In addition, incidents were reported wherein failure to continuously synchronize the voltage, frequency, and phase resulted in severe damage, i.e., electrical short circuits and grounding accidents due to pulsating transient torques upon the operation of the generator in parallel [31-34]. 
Therefore, as shown in Table 1, the implementation of DC distribution systems as an alternative to AC distribution systems has recently increased, mainly in small and medium-sized electric propulsion ships $[35,36]$.

Table 1. References of the DC-gird system in ships.

\begin{tabular}{cc}
\hline Type & Reference: Ship Name (Type, Delivery Year) \\
MS Viking Legend (Car ferry, 2009) \\
MS Viking Prestige (Car ferry, 2011) \\
MV Jaguar (General cargo ship, 2012) \\
Absis Dover (PSV, 2012) \\
Dina Star (PSV, 2013) \\
Edda Ferd (PSV, 2013) \\
BB Green (Ferry, 2015) \\
Damen Eco Liner (Tanker, 2015) \\
Edda Freya (OSV, 2016) \\
Harvey Stone (PSV, 2016) \\
Vision of the Fjords (Car ferry, 2016) \\
IJ Ferry 60, 61 (Passenger ferry, 2016-17) \\
NKT Victoria (Cable laying vessel, 2017) \\
Van Oords Nexus (Cable laying vessel, 2017) \\
FCS Alsterwasser (Ferry, 2012) \\
Ampere (Car ferry, 2014) \\
Battery main power $\quad$ Elektra (Ferry, 2017) \\
Tycho Brahe and Aurora of HH ferries (Car ferry, 2017) \\
Guangzhou Shipyard International (Cargo ship, 2017) \\
E-ferry (Car ferry, 2018)
\end{tabular}

The DC distribution system of an electric propulsion ship refers to converting the output of an AC generator to DC using a power converter installed at the rear end of the generator and then distributing it. In parallel operation, unlike an AC distribution system in which the grid connection between generators is complicated, parallel operation between grids is easily possible if only the DC voltage at the bus end is kept the same. In addition, a variable speed system can be applied that can change the speed of the generator engine according to the load of the ship due to the power conversion device installed at the generator output stage.

The biggest difference between conventional AC and DC power distribution systems is that the application of a variable speed synchronous generator engine in DC systems increases or decreases the rotational speed of the generator engine according to the load, which allows for optimal fuel consumption, thereby reducing fuel consumption and emissions during low-load operations $[37,38]$.

However, as previously mentioned, when the speed changes with respect to the load, the maintenance of a constant set reference voltage value of the automatic voltage regulator installed in the synchronous generator may lead to the following problems.

First, in the excitation system of the synchronous generator, an excessive excitation current may be supplied to the field winding, to maintain the previously-set reference voltage $[39,40]$.

Second, when the speed is changed by the synchronous generator, an over-flux phenomenon occurs due to changes in voltage and frequency; in severe cases, this may cause significant damage to the internal devices and windings of the generator [41,42].

Most of the studies conducted on the DC distribution system were focused on the feasibility of the DC distribution system in comparison with the AC distribution system [43-47]. Moreover, several studies were conducted on the enhancement of energy efficiency due to minimization of fuel consumption by the application of a variable-speed engine [28-30,37,38,48], the power conversion devices that constitute the power system of a variable speed engine, and specialized components such as propulsion motors and circuit breakers $[49,50]$. However, limited studies have been conducted on 
the protection of the internal devices and windings of a variable speed generator engine, which is a critical component of a DC distribution system.

Therefore, the aim of this study was to describe the necessity for the reference voltage control of the automatic voltage regulator with respect to the speed using the proposed neural network algorithm, for the protection of the generator in variable-speed operation.

To adjust the reference voltage in the automatic voltage control device with respect to the engine speed, a reference voltage control method was proposed for the adjustment of the value of the input variable resistance to the external resistance terminal of the automatic voltage control device using a neural network algorithm. The input and output data for the training of neural networks were experimentally measured, and the connection weight derived through training was inputted into the neural network controller for the configuration of the simulation and experimental apparatus. The output results were obtained via this procedure.

\section{Materials and Methods}

\subsection{Necessity of Reference Voltage Control of Variable Speed Generator Engine}

Most power systems in the electric propulsion ships in operation are based on the AC distribution system, and the AC distribution system operates the generator engine at a constant speed to maintain a constant generator voltage and frequency, irrespective of the load. Therefore, the fuel consumption and exhaust gas emission of the generator engine increase during low-load operation. In addition, it is difficult to synchronize the voltage, frequency, and phase in the real-time parallel operation of generators for the distribution of the ship load.

Moreover, the DC power distribution system of the variable speed synchronous generator engine can operate within the range of optimal fuel consumption according to the fuel consumption characteristics of the engine by varying the engine speed with respect to the load on the ship, as shown in Figure 2. Therefore, the fuel consumption and emissions are reduced during low-load operations. The ABB (ASEA Brown Boveri) Ltd., a global marine electric propulsion system engineering company, confirmed that fuel consumption can be reduced by up to $27 \%$, in addition to a decrease in emissions, due to the operation of "Dina Star", namely, the ship with the first onboard DC-grid system [51].

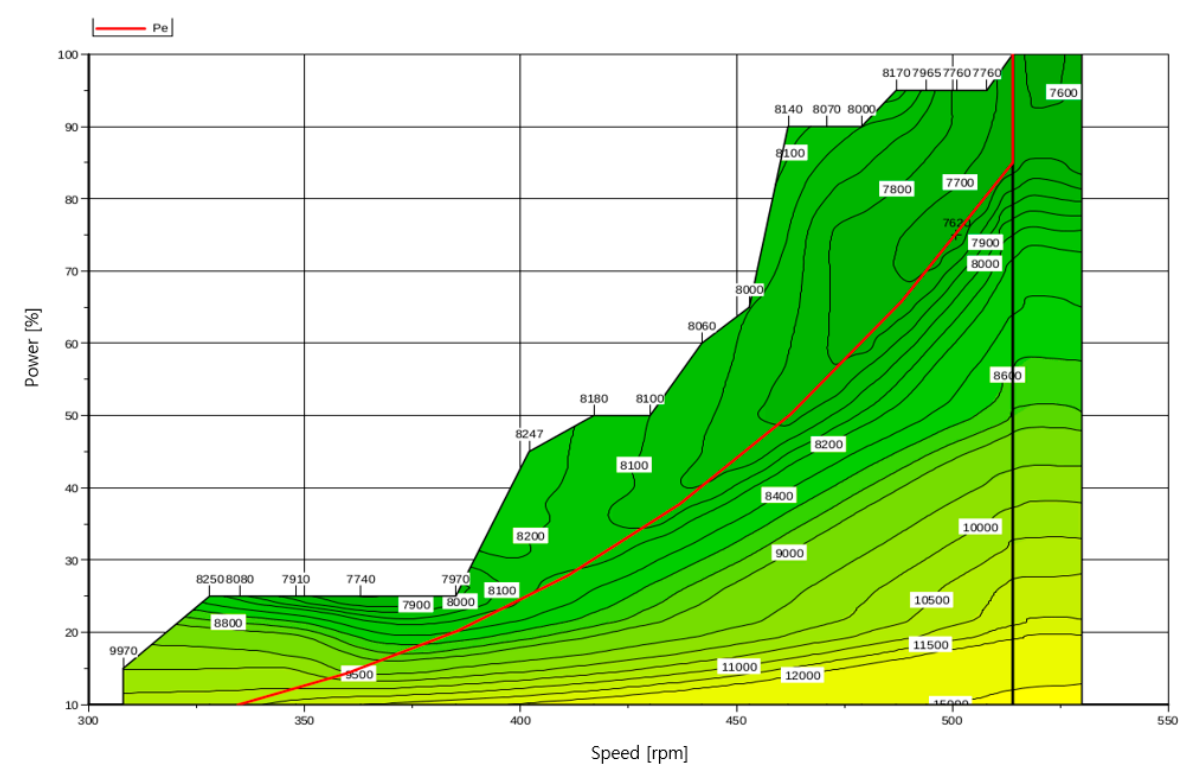

Figure 2. Comparison of fuel consumption according to engine speed change. 
During parallel operation, synchronization can be easily conducted by matching the value of the voltage using a power converter installed at the rear of the generator. Figure 3 presents a comparison of the power distribution systems in electric propulsion ships.

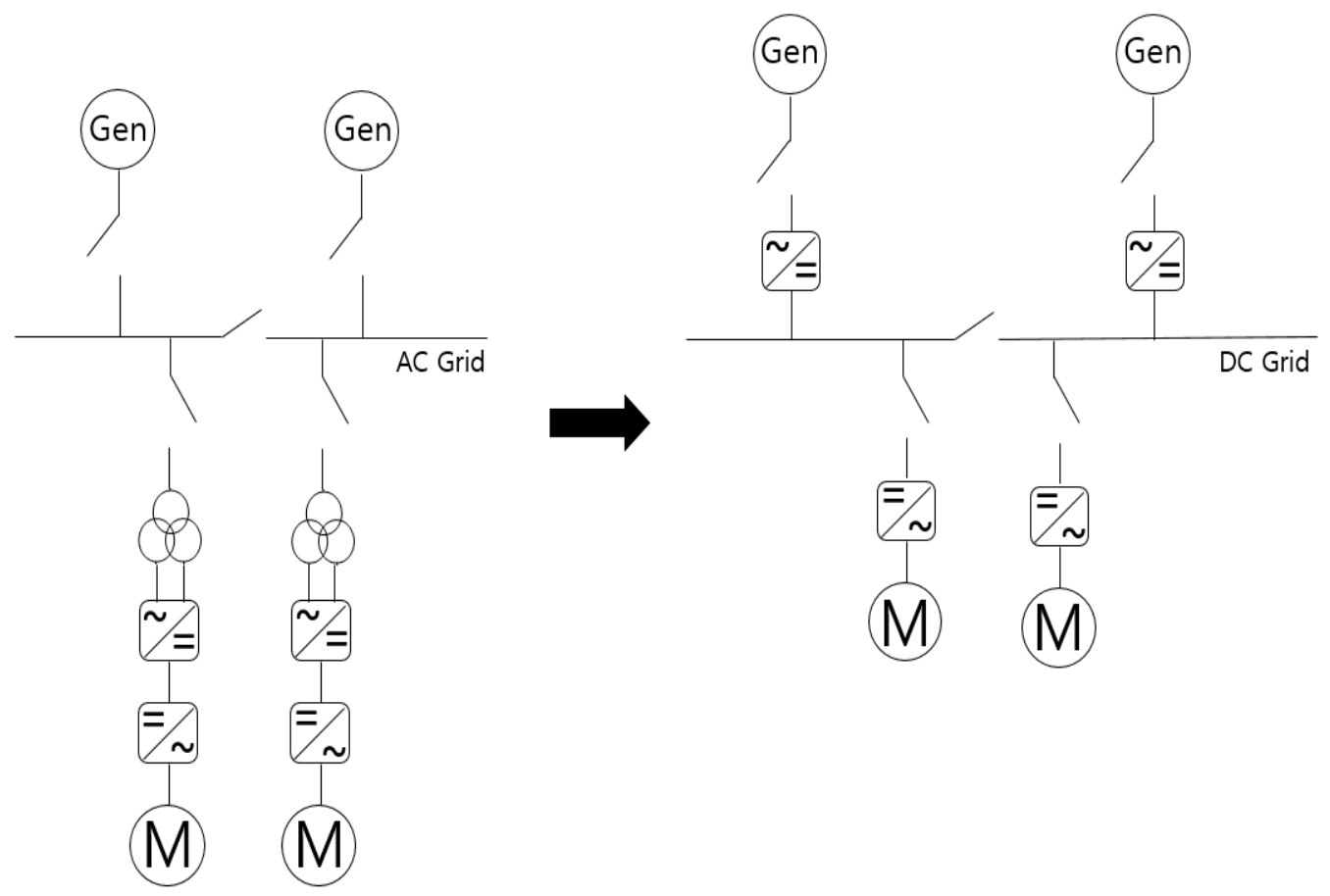

Figure 3. Comparison of distribution systems in electric propulsion system of ships.

However, in a DC distribution system with a variable speed synchronous generator engine, the reference voltage of the generator output side should be adjusted with respect to the speed, for the following reasons.

When the reference voltage of the generator is kept constant, a decrease in the rotational speed of the variable speed synchronous generator engine due to sudden load fluctuations in a DC-grid ship may cause over-flux or overexcitation, thus resulting in damage to the internal devices or windings of the generator.

A change in over-flux refers to the excessive amount of magnetic flux generated by the rotor, as expressed by an equation of the induced electromotive force (EMF), namely, Equation (1).

$$
\mathrm{V}=4.44 k f \varphi
$$

Here, $\mathrm{V}$ is induced electromotive force (generator output voltage), $k$ is winding factor, $f$ is frequency, and $\varphi$ is magnetic flux.

The above equation can be converted into an equation for magnetic flux, as shown in Equation (2).

$$
\varphi=4.44 \times \frac{\mathrm{V}}{f}
$$

From Equation (2), it can be seen that the magnitude of the magnetic flux is dependent on the voltage and frequency, where a large magnetic flux refers to the case wherein the magnitude of the generator output voltage increases and the frequency decreases due to a decrease in the rotational speed of the generator. When the rotational speed of the variable speed synchronous generator engine suddenly decreases, as in the above assumption, the magnitude of the magnetic flux supplied to the generator increases in accordance with a decrease in frequency. 
Although the generator is equipped with an over-flux limiter to prevent internal damage by overexcitation, given that the protection technique is based on the $\mathrm{V} / \mathrm{Hz}$ ratio, the faulty state of the interrupted relay cannot be easily determined upon the occurrence of a disturbance that increases in proportion to the frequency and voltage, when the $\mathrm{V} / \mathrm{Hz}$ ratio is kept constant [52].

When an excessive magnetic flux density is maintained in the internal iron core of the generator for a long time-period, the conduction path of the magnetic flux is saturated, and the leakage magnetic flux increases. The generated leakage magnetic flux then induces an eddy current in the non-stacked portion of the iron core. In particular, when overheating occurs due to eddy currents in the bolts and brackets that fix the iron core to the non-stacked part, thermal expansion occurs, and the force required to fix the iron core in place is diminished, thus resulting in vibrations within the iron core. Such vibrations within the iron core cause friction between the iron cores, thus damaging the insulating material surrounding the iron core. Moreover, cases of severe damage to the internal structure of the generator were reported, as shown in Figure 4 [31,53].
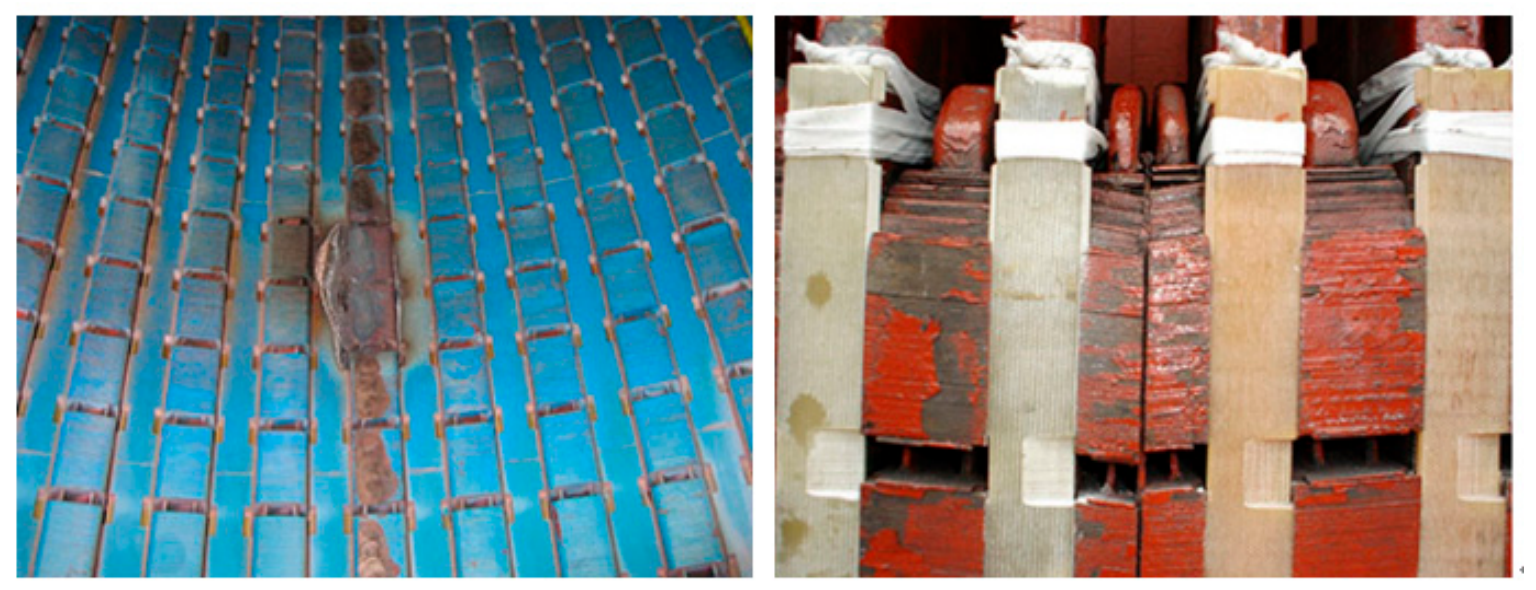

Figure 4. Damaged internal windings of the generator.

When the rotational speed of the variable speed synchronous generator engine is reduced, the exciter can supply an excessive excitation current to the generator rotor to maintain the generator output voltage at the previously-set value. With an increase in the excitation current supplied to the rotor windings, the heat generated from the windings increases, which may limit the stable operation of the generator.

Therefore, when a variable speed synchronous generator engine is applied to a DC distribution system, the reference voltage should be appropriately adjusted by the automatic voltage regulator of the generator to stably maintain the output voltage by supplying the appropriate amount of magnetic flux and excitation current to the generator windings. Moreover, it is necessary to control the generator reference voltage to protect the windings and internal structure of the generator.

\subsection{Methodology}

The overall control process of the reference voltage with respect to speed using a neural network is shown in Figure 5.

\subsubsection{Step 1: Data Acquisition}

To control the reference voltage with respect to changes in the speed of the variable speed generator engine using a neural network algorithm, the input/output data for the training of the neural network are required. In this study, the input pattern for the training of the neural network was set as the rotational speed of the generator, and the output pattern was set as the input current value to the 
potentiometer. The synchronous power generation system installed on the testbed was used to measure the actual value.
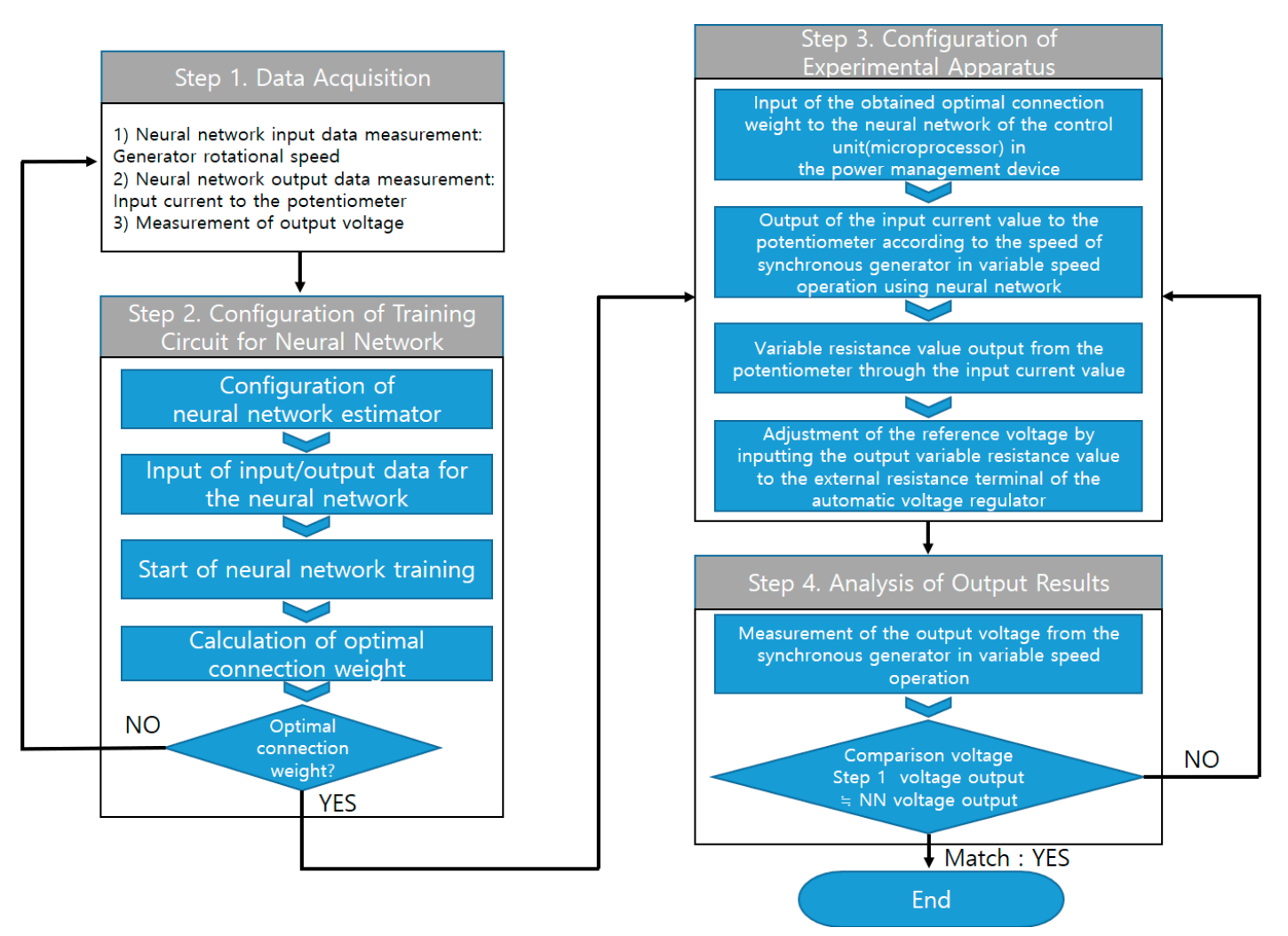

Figure 5. Reference voltage control with variable speed synchronous generator engine.

The speed of the generator, which was considered as the input pattern, was measured using a pickup sensor. The input current of the potentiometer, which was considered as the output pattern, was set to match the reference voltage to be output by the automatic voltage regulator with respect to the rotational speed of the generator, in advance. A potentiometer for the variable resistance output was installed to adjust the variable resistance value at this time. Upon obtaining the current value for the setting of the reference voltage with respect to the rotational speed, the potentiometer outputs an appropriate variable resistance value and supplies it to the reference voltage control circuit of the automatic voltage regulator.

To output the variable resistance value for the setting of the reference voltage matched to the rotational speed of the generator, as shown in Figure 6, 4-20 mA was supplied to the input side of the potentiometer using a power supply. The variable resistance value output from the potentiometer is then inputted into the external resistance terminal of the automatic voltage regulator, and the potentiometer input current value is adjusted to obtain the matched voltage by the operation of the synchronous generator and measurement of the actual generator voltage.

\subsubsection{Step 2: Training Configuration for Neural Network}

The rotational speed of the synchronous generator and the input current value of the potentiometer obtained through actual measurements, as detailed in Section 2.2.1, were sampled to obtain the optimal connection weight through the training procedure, by the application of the backpropagation algorithm in the neural network configured with MATLAB/Simulink as shown in Figure 7. 


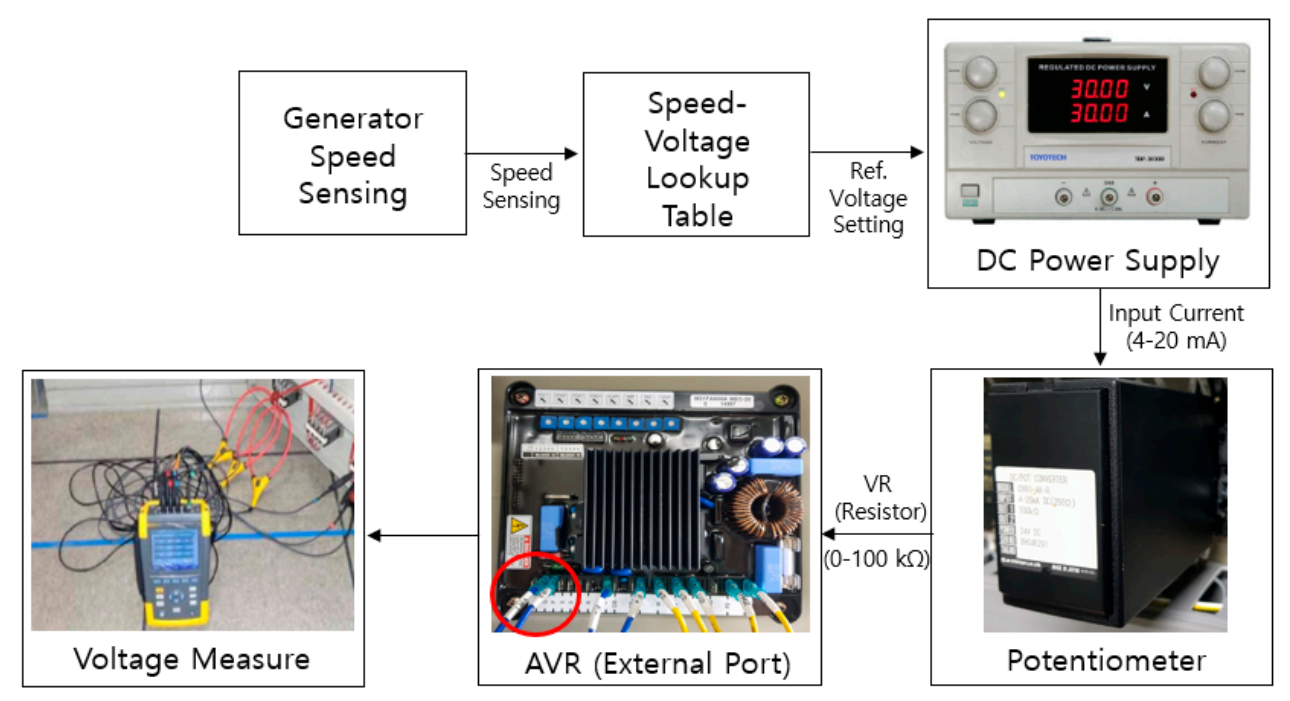

Figure 6. Configuration of input/output data measurement for neural network training.

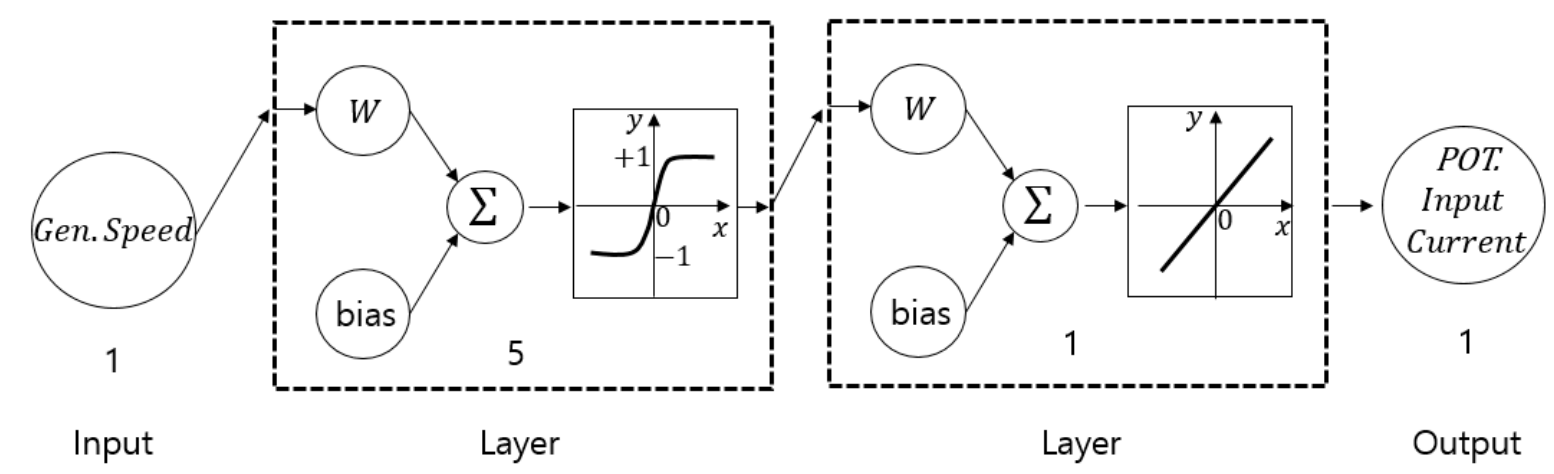

Figure 7. Block diagram of the neural network developed in this study.

With MATLAB/Simulink, one hidden layer with five nodes is configured through repeated training processes. A tan-sigmoid function was applied as the activation function of the hidden layer, and a linear function was applied as the activation function of the output layer. The tan-sigmoid function applied as the activation function can be expressed as Equation (3) $[54,55]$.

$$
f(x)=\frac{2}{1+e^{-2 x}}-1
$$

The input current of the potentiometer can be expressed as Equation (4) using the optimal connection weight obtained through the backpropagation algorithm of the neural network.

$$
\hat{C}_{s}(k)=\left[F_{j}\left(X_{i} W_{i j}+B_{j}\right)\right]
$$

where $\hat{C}_{s}(k)$ denotes the input current of the potentiometer as the output data; $i$ denotes the number of nodes in the input layer; $j$ denotes the number of nodes in the hidden layer; $k$ denotes the number of nodes in the output layer; $F_{j}$ denotes the active function of the hidden layer; $X_{i}$ denotes the rotor speed matrix of the generator; $W_{i j}$ denotes the connection weight matrix between the input layer and the hidden layer; $W_{j k}$ denotes the connection weight matrix between the input layer and the hidden layer; $B_{j}$ denotes the hidden layer bias matrix; and $B_{k}$ denotes the output layer bias matrix.

As shown in Figure 8, given that the connection strength could be determined as inappropriate due to an error arising from the comparison of the input current value of the potentiometer (the output of the neural network) with the target value, an algorithm was applied to minimize the error by re-training 
the neural network through the backpropagation of the generated error in the neural network. In the process, when the optimum connection weight is obtained, the next step is started. If the optimum connection weight is not obtained, the input/output data are re-checked for the re-training of the neural network [56,57].

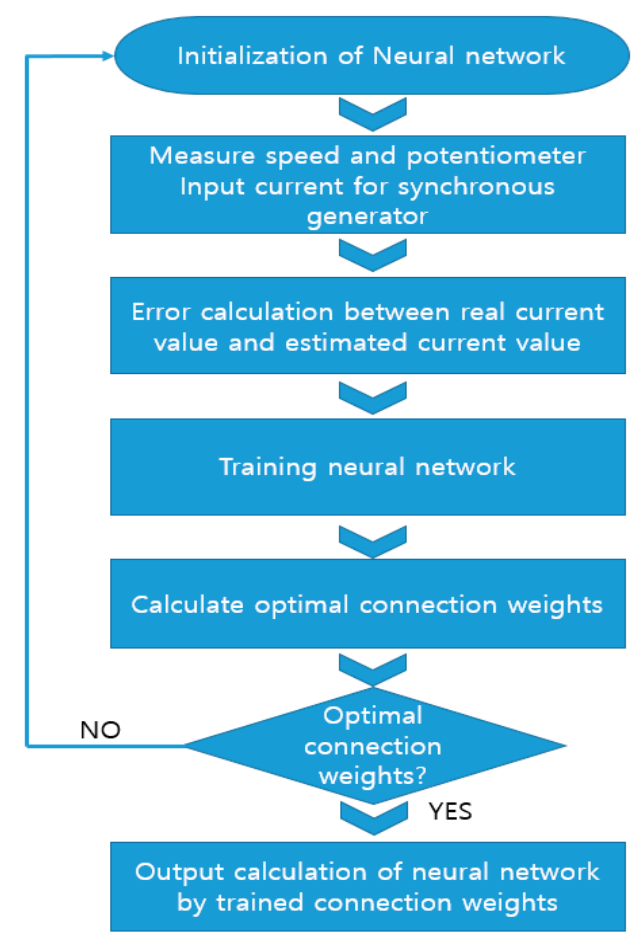

Figure 8. Flowchart of training algorithm for neural network.

Figure 9a presents the rotational speed data of the variable speed synchronous generator engine, which was used as the input pattern of the neural network; Figure $9 \mathrm{~b}$ presents the data of the potentiometer input current, which was used as the output pattern. Figure $9 \mathrm{c}$ presents the output result of the current output with respect to the input of the potentiometer, with the speed command of the synchronous generator, which was the input value of the neural network. Moreover, the speed changed in the order of $1800 \rightarrow 1100 \rightarrow 1800 \mathrm{rpm}$ after the configuration of a neural network controller input with the connection weight, thus validating the connection weight of the neural network derived by the backpropagation algorithm.

The simulation results shown in Figure $9 \mathrm{c}$ reveal that the target potentiometer current value was accurately outputted with respect to the changes in the speed of the variable speed synchronous generator engine, thereby validating the connection weight value obtained through the training of the neural network.

\subsubsection{Step 3: Configuration of Experimental Apparatus}

The optimal connection weight obtained by the neural network was inputted into the neural network controller of the power management device. The input current value of the potentiometer with respect to the speed of the variable speed synchronous generator engine is the output of the control unit of the power management device. The reference voltage was then adjusted by inputting the variable resistance value output from the potentiometer to the external resistance terminal of the automatic voltage regulator, with respect to the input current.

The overall system configuration of the variable speed synchronous generator engine used in the application of reference voltage control method using a neural network is shown in Figure 10. 


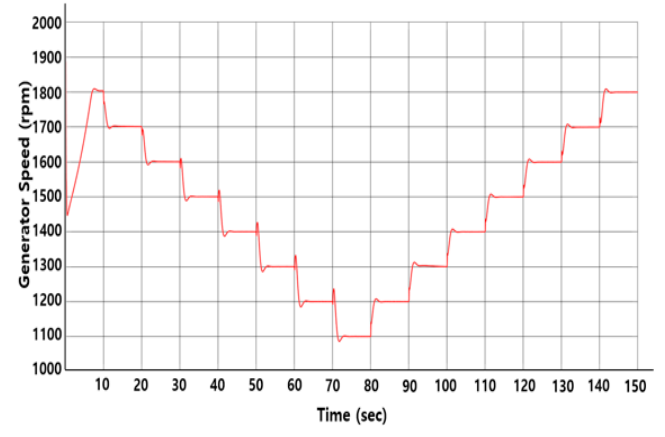

(a)

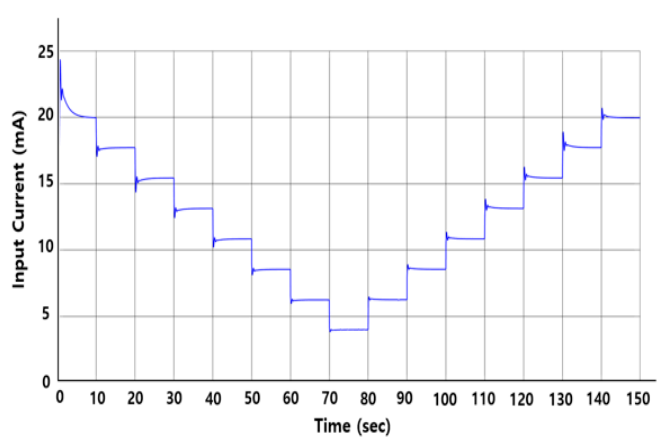

(b)

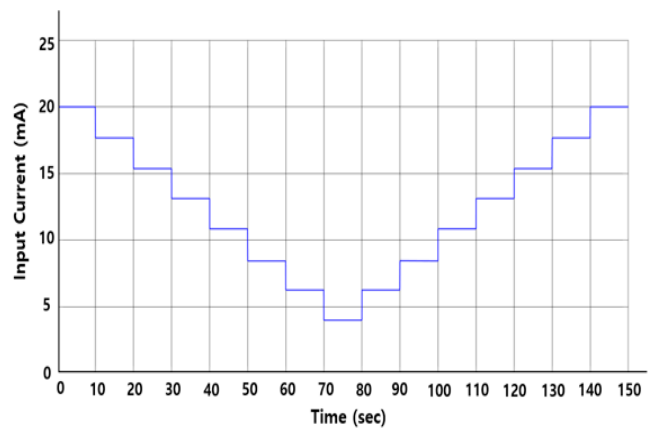

(c)

Figure 9. (a,b) Input/output training data for the neural network and (c) training output result with respect to time.

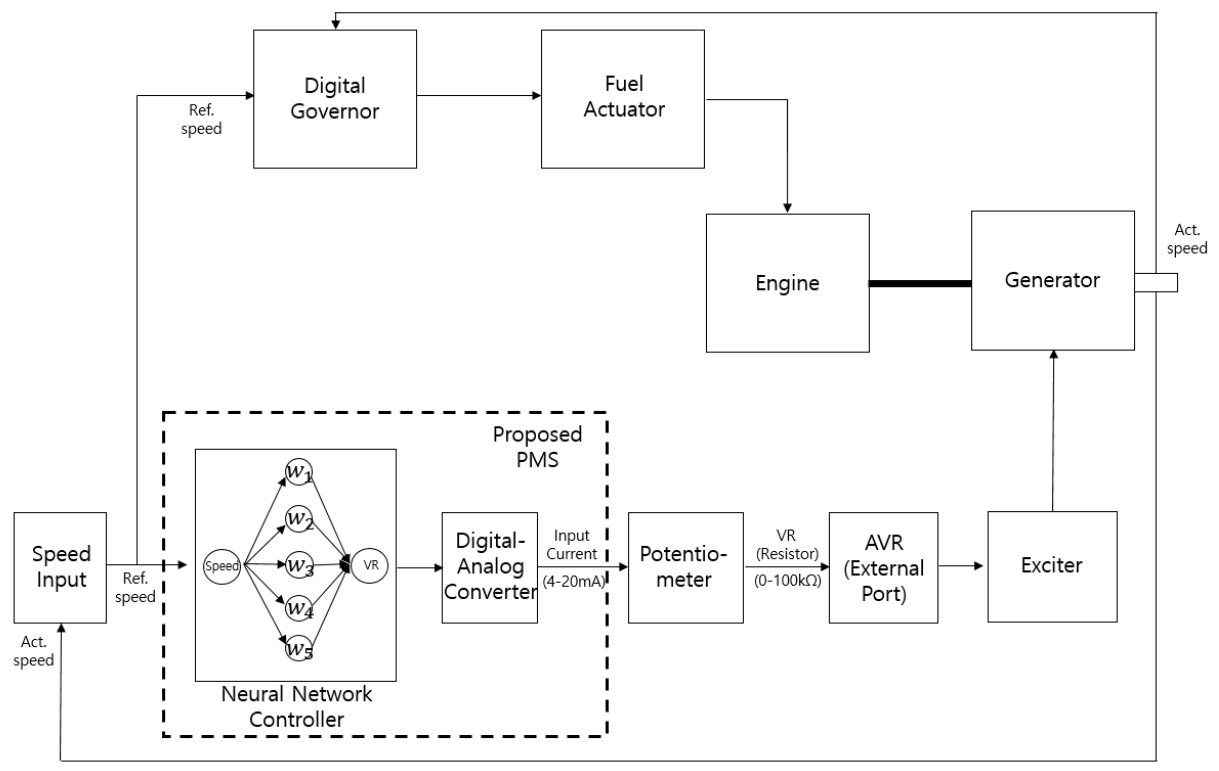

Figure 10. Overall system configuration of the variable speed synchronous generator engine in the reference voltage control method using a neural network.

The experimental apparatus was configured in the same manner as the variable speed synchronous generator engine under the application of reference voltage control using a neural network. Figure 11 presents the setup of the experimental apparatus. The experimental apparatus consisted of a variable speed engine, a synchronous generator, a power management system, a potentiometer, and an automatic voltage regulator. The power management device with the applied neural network controller included a microprocessor system (control unit), programmable logic circuit (PLC), power supply, and communication device. 


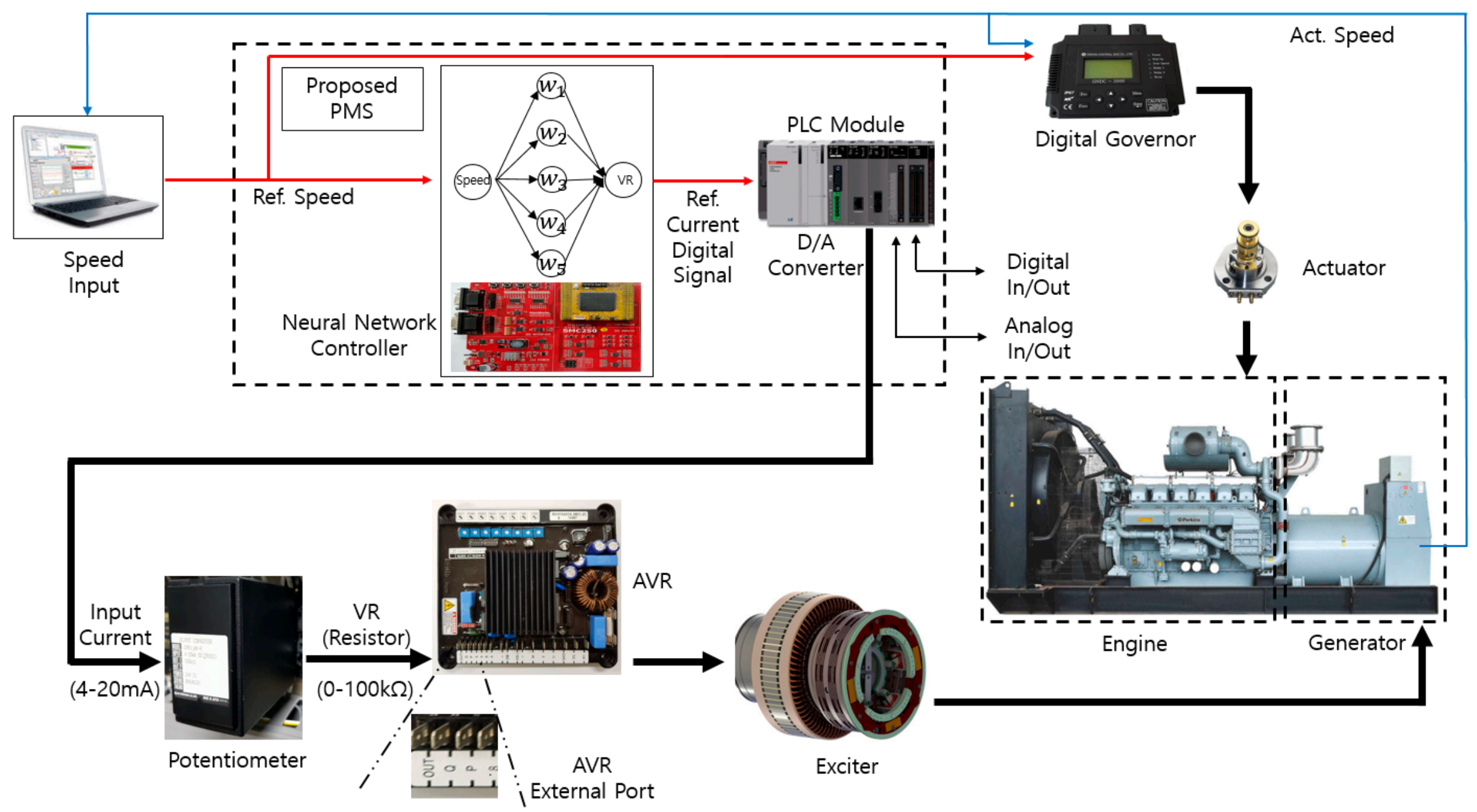

Figure 11. Experimental setup of the synchronous power generation system in variable-speed operation based on the proposed neural network. 
Table 2 lists the system components for the experiment and their corresponding roles.

Table 2. Components of the experimental apparatus and their functions.

\begin{tabular}{ccc}
\hline Item & Model & Description \\
\hline Diesel Engine & P158LE-III & $400 \mathrm{~kW}$ \\
Alternator & MJB 355SB4 & $440 \mathrm{VAC}, 60 \mathrm{~Hz}$ \\
Digital Governor & GNDC-1000 & Engine Control \\
Microprocessor & TMS320F28377D & Neural Network Controller \\
PLC Module & XGB XBC-DN32 & Analog, Digital data in/out \\
Communication Device & ADAM 4520 & RRS485 to RS232 Converter \\
Potentiometer & CVR1-AK-R & AVR External resistance control \\
AVR & M31FA600A MEC-20 & Voltage control \\
\hline
\end{tabular}

Variable Speed Synchronous Generator Engine

The variable speed synchronous generator engine, as configured in this study, was a diesel engine with a brushless synchronous generator with the following system specifications: rated output of $400 \mathrm{~kW}$, rated voltage of $440 \mathrm{~V}$, and rated speed of $1800 \mathrm{rpm}$. The variable speed operation range was set as 1100-1800 rpm, because the L.O (Lubricating Oil) and coolant pump are self-attached type engines, and when operating in the range of $1100 \mathrm{rpm}$ or less, the safety of engine operation will be dramatically reduced due to the drop in L.O and coolant pressure. Therefore, in this study, the operating range is set to $1100-1800 \mathrm{rpm}$. The engine speed and generator output voltage were controlled according to the output speed command value from the neural network controller of the power management system.

Power Management System

- Control system

The neural network was trained using the input and output data obtained from actual measurements. Moreover, a neural network controller was configured to calculate the input current value of a potentiometer that was installed on the microprocessor in the power management device, with respect to the input speed, by the calculation of the optimal connection weight through training, which was then applied to the synchronous power generation system.

The control system of the power management device acts as the control unit of the entire system, carries out the calculations via the neural network controller based on the input data, and outputs the calculation results. Given that such an operation process requires a high processing speed for floating-point operations and excellent control reliability, a high-performance 32-bit dual-core controller (TMS320F28377D, Texas Instruments) was used.

\section{- $\quad$ PLC}

The PLC received the output data calculated by the microprocessor system and converted to 4-20 mA, which is the input power of the potentiometer, via a digital/analog converter. The PLC then transmits the digital and analog input/output data of the variable-speed engine and the generator to the power management device.

- Communication device

The speed of the variable-speed engine is transmitted using the RS485 serial communication method; in this study, an "RS485 to RS232" converter was employed to connect the transmitted data to the D-SUB 9-pin connector for the RS232 communication of the microprocessor system board. 


\section{Potentiometer}

To adjust the generator reference voltage with respect to the engine speed, a variable resistance value was inputted into the external terminal of the automatic voltage regulator. A potentiometer, as shown in Figure 12a, was additionally installed to change the variable resistance value according to the calculation result of the neural network with respect to the speed. The reference voltage was set with respect to the speed, and the variable resistance value for outputting the reference voltage via the neural network controller was adjusted by the variation of the input current value of the potentiometer.

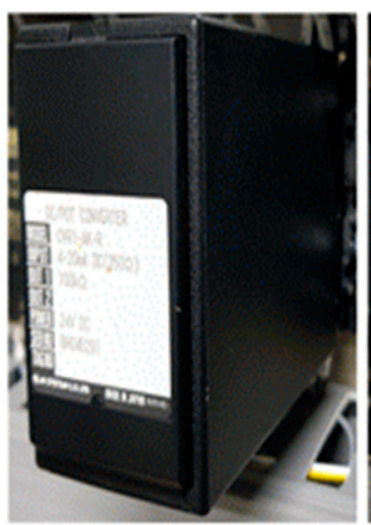

(a)

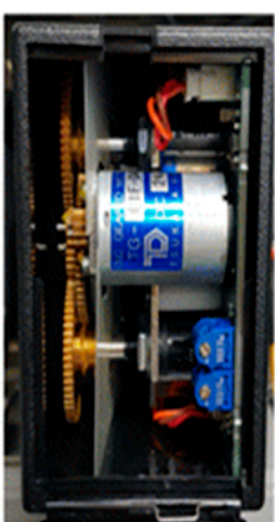

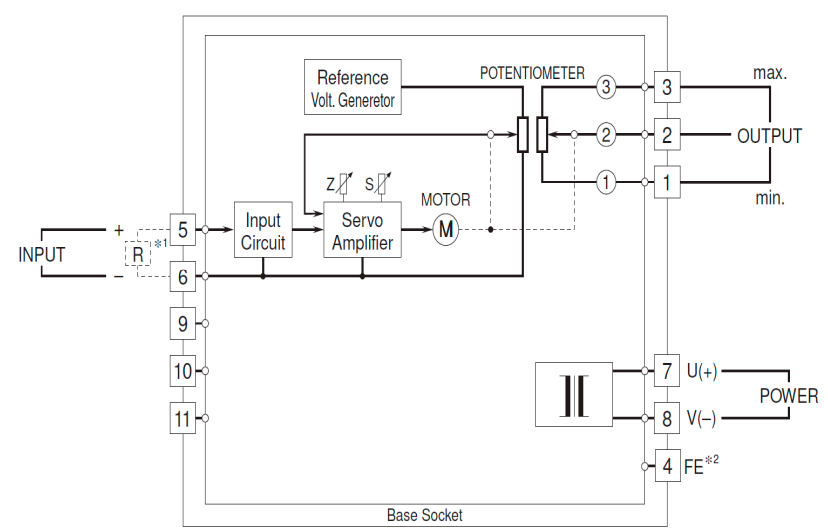

(b)

Figure 12. (a) Physical structure and (b) internal circuit diagram of potentiometer.

Figure $12 \mathrm{~b}$ presents the internal circuit of the potentiometer. The installed potentiometer was sourced by a DC supply voltage of $24 \mathrm{~V}$ and supplied power to the internal circuit and servo motor. The current input circuit converts the input current of 4-20 mA input into a voltage signal through a resistance of $250 \Omega$ installed at the front of the current, and then transmits the voltage signal to the comparator of the servo motor driver circuit. The servo motor driver circuit adjusts the rotation angle of the servo motor in proportion to the size of the input voltage signal. Given that the variable resistance potentiometer was directly connected to the drive shaft of the servo motor, the output variable resistance value was adjusted by adjusting the voltage divider ratio of the variable resistance using a current signal of 4-20 mA.

Reference Voltage Control Unit of the Automatic Voltage Regulator

Figure 13a presents the appearance of the automatic voltage regulator used in the experiment, and Figure $13 \mathrm{~b}$ shows the reference voltage control circuit in the automatic voltage regulator. If the divided voltage is lowered by adjusting the variable resistance value output from the potentiometer, the differential amplifier circuit determines that the generator output voltage is lower than the reference voltage, and outputs a positive voltage to increase the excitation current, thus resulting in an increase in the output voltage of the generator. Conversely, if the divided voltage is increased by adjusting the variable resistance value output from the potentiometer, the differential amplifier circuit outputs a negative voltage to reduce the excitation current, thus resulting in a decrease in the output voltage of the generator. The size of the generator reference voltage was adjusted with respect to the variable speed based on this principle.

As shown in Figure 13b, the automatic voltage regulator is a device that maintains a constant reference voltage by the control of the excitation current supplied to the generator excitation system, and its internal circuit consists of a voltage input circuit for the detection of the generator output voltage, a differential amplifier circuit, and a semiconductor switching circuit to output excitation current signals. The input voltage circuit receives the generator output voltage through an instrument transformer and converts it into a DC voltage through a diode rectifier and smoothing circuit. The differential amplifier 
circuit supplies the non-inverting input part of the circuit with an internal reference voltage and inputs the generator output voltage converted to the DC voltage by the voltage input circuit to the inverting input part of the circuit. Thereafter, it differentially amplifies the output voltage via a comparator, and outputs the value to the semiconductor switch.

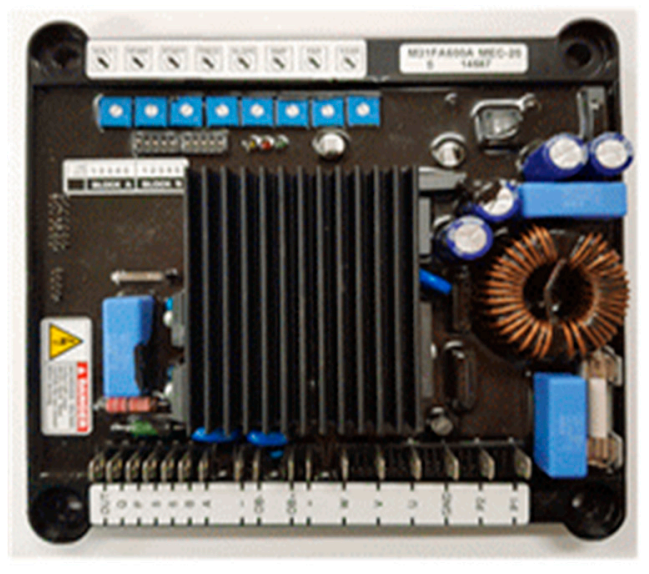

(a)

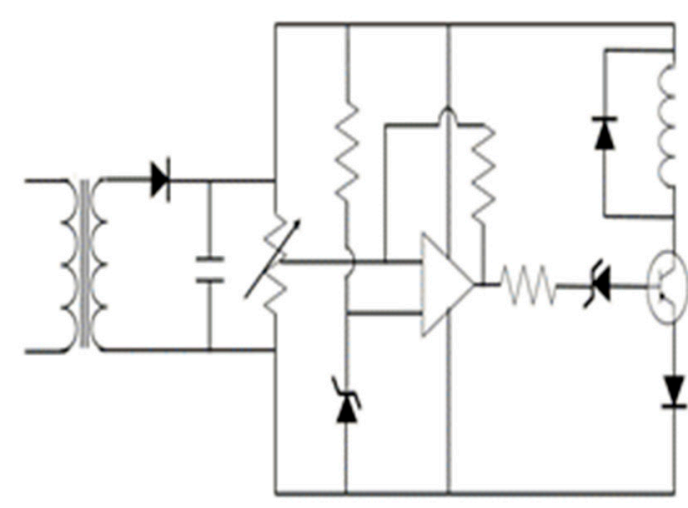

(b)

Figure 13. (a) Internal structure of automatic voltage regulator, and (b) the reference voltage control circuit.

\subsubsection{Step 4: Analysis of Output Results}

By measuring the output voltage of the variable speed synchronous generator engine, it can be determined whether the set voltage is appropriately outputted. If not, the process is repeated by probing the neural network controller in the control unit and the input data. If the output voltage of the synchronous generator is confirmed to be within the acceptable range, the entire configuration of the reference voltage control process is considered as acceptable.

\section{Experimental Results}

The application of the variable speed synchronous generator engine significantly improves the energy efficiency and decreases emissions of a DC distribution system. Therefore, an increase in the number of cases of applying the variable speed synchronous generator engine in ships is expected in the implementation of asynchronous generators in variable-speed operation in ships, and the reference voltage control for the protection of the synchronous generator with respect to speed is critical in such applications.

To adjust the reference voltage with respect to the speed of the synchronous generator in the variable speed synchronous generator engine operation, the neural network controller was applied with the connection weight obtained by training the neural network using the generator speed as input data. The potentiometer input current, which was considered as output data, was composed of one hidden layer and five internal nodes, with the tan-sigmoid function set as the output function of the hidden layer.

The operating range of the variable speed synchronous generator engine was set as 1100-1800 rpm, and the experiment was conducted by classification into (1) the case wherein the speed is increased or decreased by $100 \mathrm{rpm}$ as the input data used for training the neural network, and (2) the case wherein an arbitrary speed command is inputted.

When the speed of the variable speed synchronous generator engine in operation was increased by $100 \mathrm{rpm}$ within the range of $1100-1800 \mathrm{rpm}$, as shown in Figure 14a, the result of the input current supplied to the potentiometer was outputted, as shown in Figure 14b. Figure 14c,d present the experimental results with respect to the output of the input current of the variable resistance 
potentiometer that generated the external resistance value of the automatic voltage regulator when the speed of the variable speed synchronous generator engine was decreased by $100 \mathrm{rpm}$ within the range of 1800-1100 rpm.

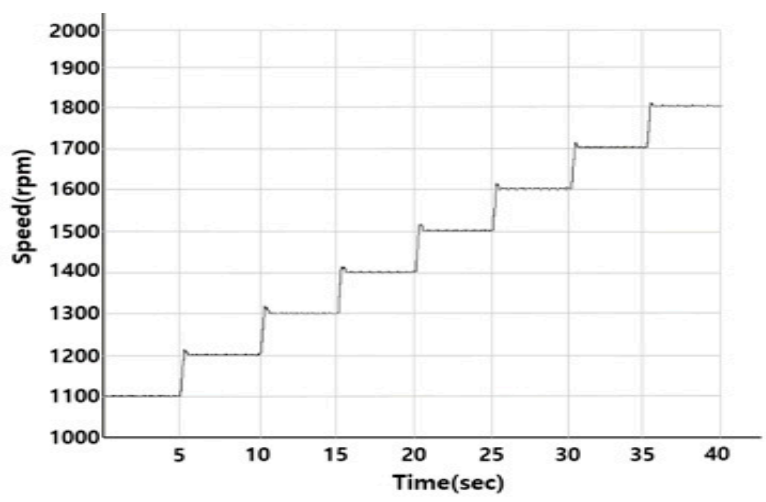

(a)

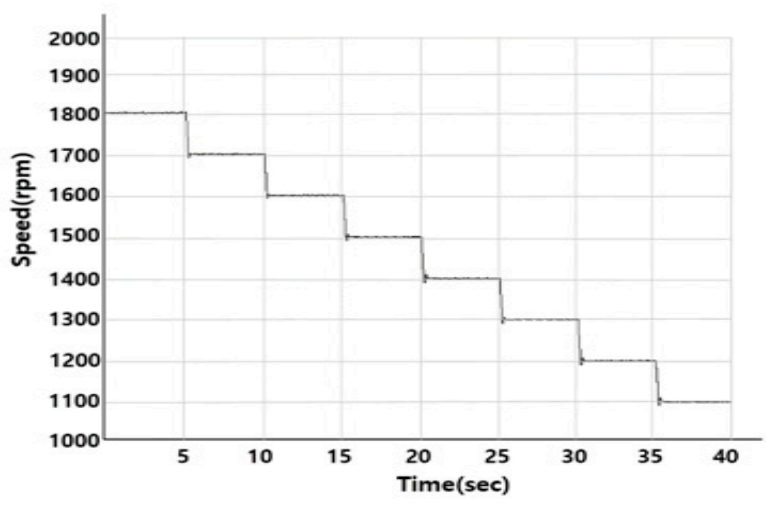

(c)

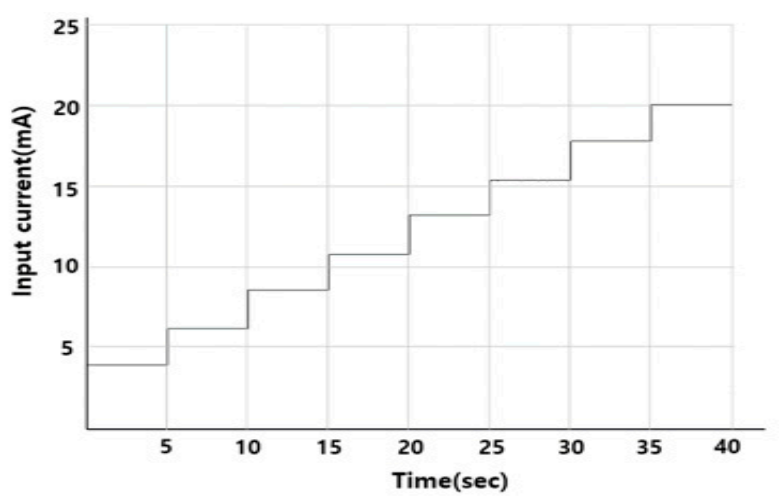

(b)

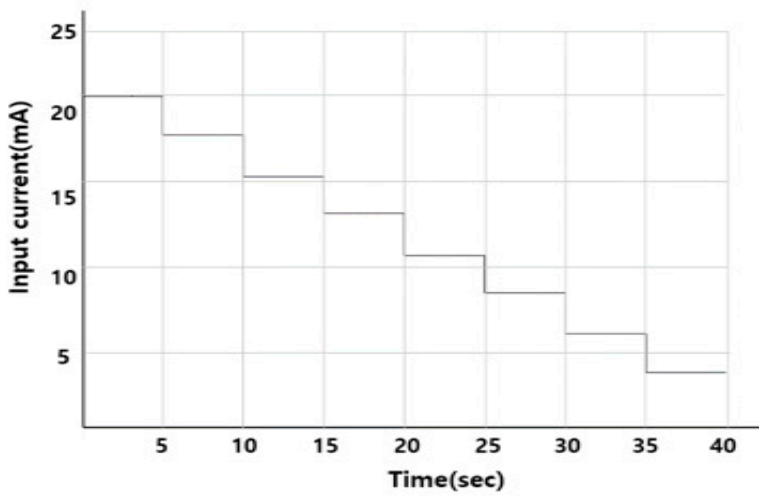

(d)

Figure 14. The output result of speed when the generator speed increases $(\mathbf{a})$, decreases(c) and (b) is the output result of the potentiometer input current with respect to increasing speed, (d) is the output result of the potentiometer input current with respect to decreasing speed.

From the analysis of the experimental outputs, the output value of the input current was found to immediately and accurately reach the target value within the range of 4-20 $\mathrm{mA}$, with minimal delay in the initial response speed with respect to changes in the speed of the generator. Therefore, the output voltage of the synchronous generator was outputted within the range of the set reference voltage from 250 to $440 \mathrm{~V}$, as shown in Table 3.

Table 3. Experimental results of the generator reference voltage with respect to changes in the system speed using the neural network controller.

\begin{tabular}{ccccc}
\hline $\begin{array}{c}\text { Generator Engine } \\
\text { Speed (rpm) }\end{array}$ & $\begin{array}{c}\text { Generator Voltage } \\
\text { (VAC) }\end{array}$ & $\begin{array}{c}\text { Generator } \\
\text { Frequency }(\mathbf{H z})\end{array}$ & $\begin{array}{c}\text { Potentiometer Input } \\
\text { Current (mA) }\end{array}$ & $\begin{array}{c}\text { AVR External } \\
\text { Resistance Value (k } \mathbf{\Omega})\end{array}$ \\
\hline 1100 & 251 & 36.7 & 4.0011 & 4.15 \\
1200 & 279 & 40 & 6.2388 & 18.22 \\
1300 & 306 & 43.3 & 8.6048 & 33.67 \\
1400 & 331 & 46.7 & 10.7804 & 47.1 \\
1500 & 360 & 50 & 13.2004 & 62.9 \\
1600 & 387 & 53.3 & 15.3152 & 75.9 \\
1700 & 414 & 56.7 & 17.7208 & 91.3 \\
1800 & 443 & 60 & 19.9908 & 98.5 \\
\hline
\end{tabular}


Figure 15a shows the generator speed output when a random speed command is given to the generator and Figure $15 \mathrm{~b}$ presents the output results of the potentiometer input current for the setting of the reference voltage of the generator when the speed command of the synchronous generator was continuously changed to an arbitrary value that was not previously used for neural network training. Moreover, for an input speed command that was not previously used for the neural network training, the potentiometer input current was calculated by the connection weight configured in the neural network controller, thus resulting in the output of an appropriate generator reference voltage.

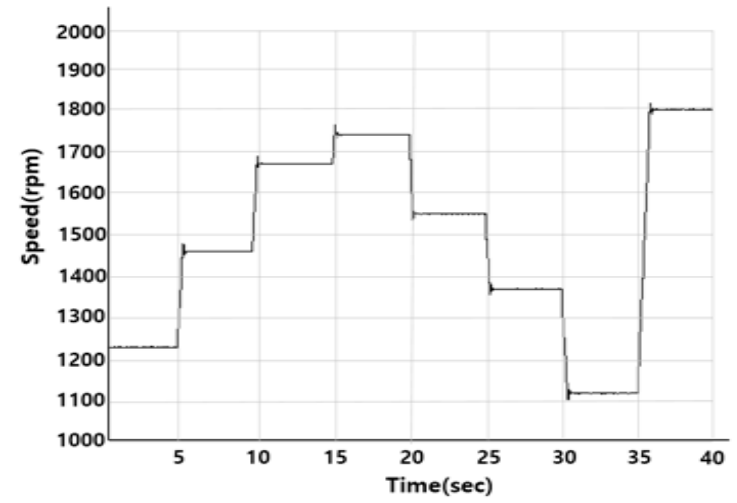

(a)

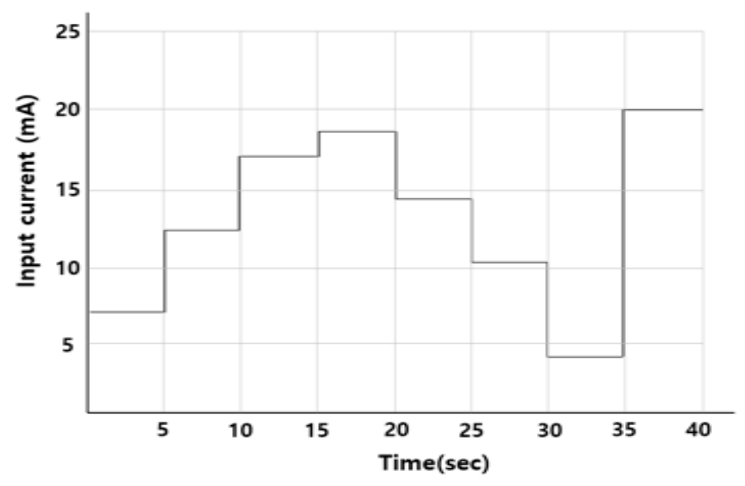

(b)

Figure 15. (a) random speed of generator, (b) output results of the potentiometer input current with respect to random speed command values.

The experimental results revealed that the reference voltage of the generator varied when adjusting the external resistance value of the automatic voltage regulator with respect to the speed using the neural network controller, as shown in Table 3; Figure 16 shows the result of confirming that the output voltage value changes as shown in Table 3 when the speed of the generator is increased from $1100 \mathrm{rpm}$ to $100 \mathrm{rpm}$. The voltage output result according to the speed change of the generator is shown in 8 sections from 1100 rpm in Figure 16a to 1800 rpm in Figure 16h.

The result of testing was the output voltage of the generator according to the increase and decrease of the speed according to the load change of the variable speed engine system based on the load scenario of the actual 5500TEU Reefer Container in the test bed. Load Scenario was applied by scaling down the actual ship's load according to the test bed, and the load data is shown in the Table 4.

Table 4. The load profile applied to the experiment (5500TEU Reefer Container ship).

\begin{tabular}{ccc}
\hline Load(kW) & Scale down Load(kW)/Pattern & Energy Source \\
\hline 1423.7 & 125(Normal seagoing without reefer) & Only DG \\
\hline 4153.7 & 357(Normal seagoing with reefer) & Only DG \\
\hline 2148.1 & 187(Port in/out without thruster) & Only DG \\
\hline 3860.4 & 332(Port in/out with thruster) & Only DG \\
\hline 3714.6 & 320(Loading/Unloading) & Only DG \\
\hline
\end{tabular}




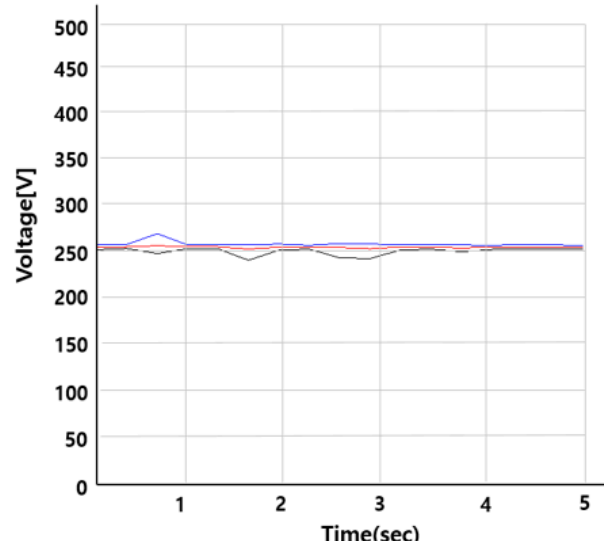

(a) 1100 (rpm), $251(\mathrm{~V})$

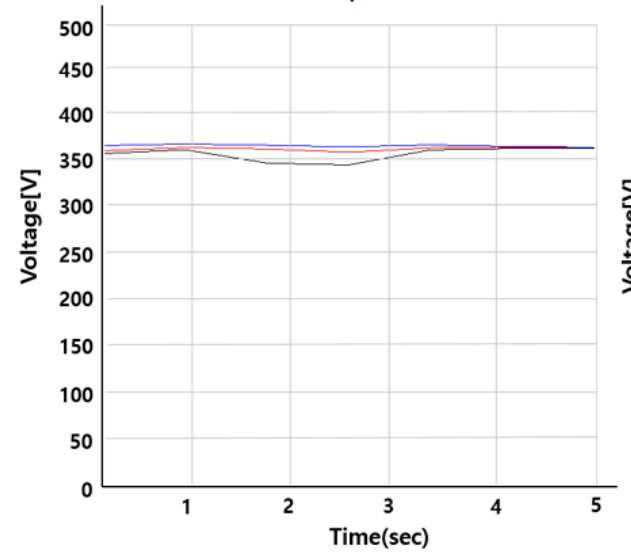

(e) 1500 (rpm), 360 (V)

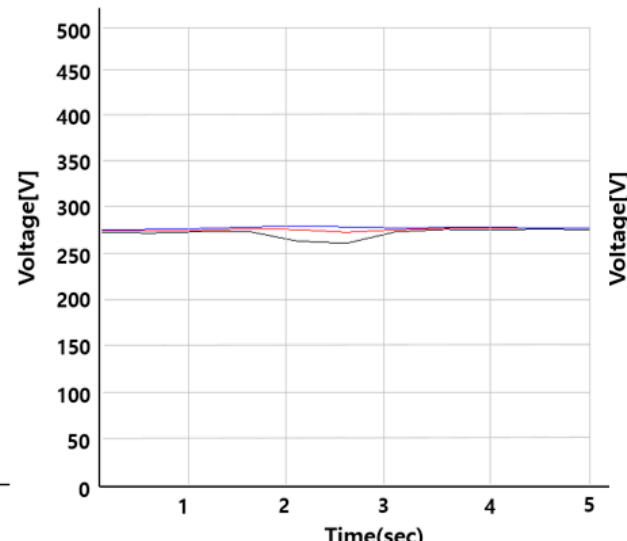

(b) 1200 (rpm), $279(\mathrm{~V})$

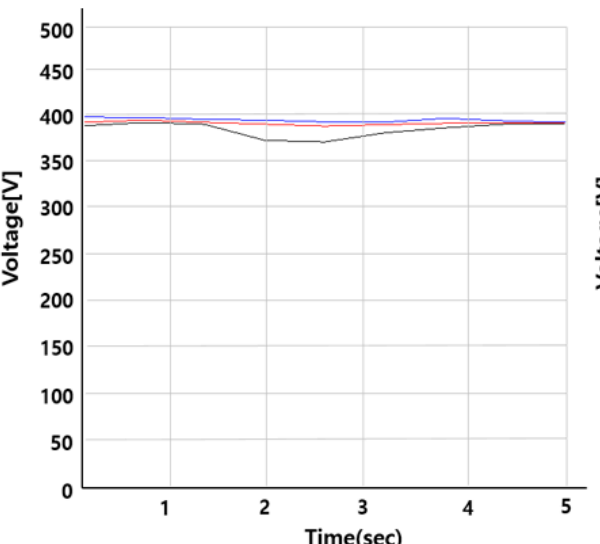

(f) $1600(\mathrm{rpm}), 387(\mathrm{~V})$

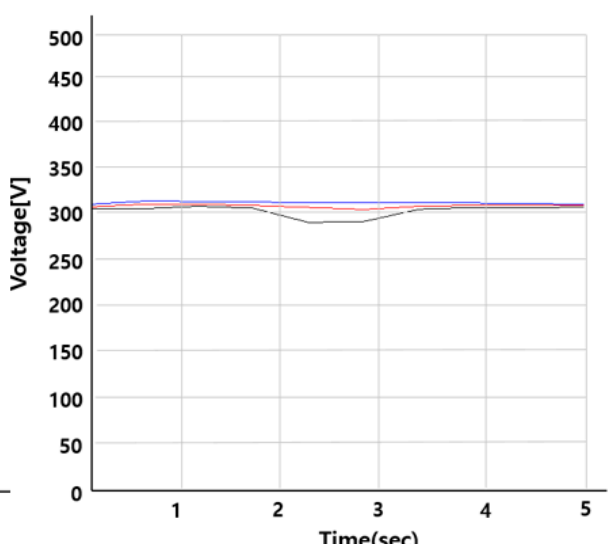

(c) $1300(\mathrm{rpm}), 306(\mathrm{~V})$

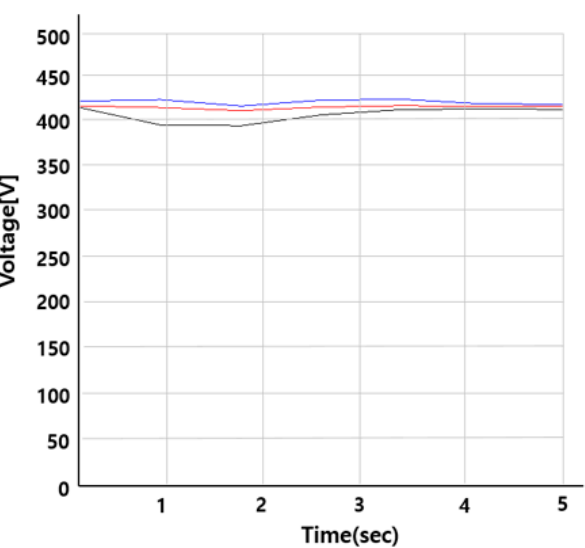

(g) $1700(\mathrm{rpm}), 414(\mathrm{~V})$

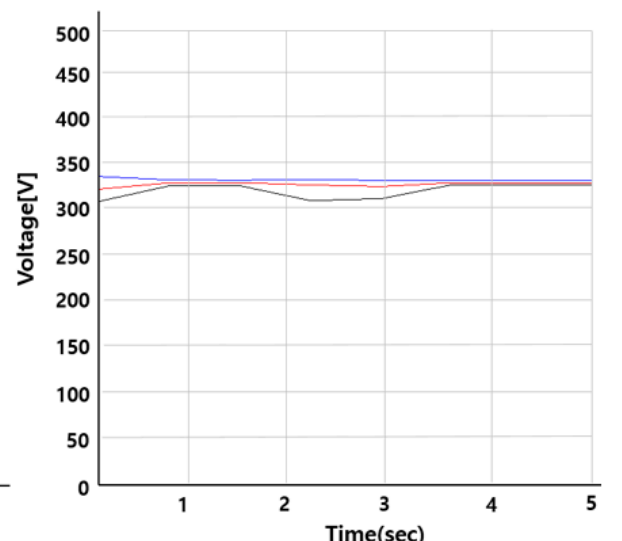

(d) $1400(\mathrm{rpm}), 331(\mathrm{~V})$

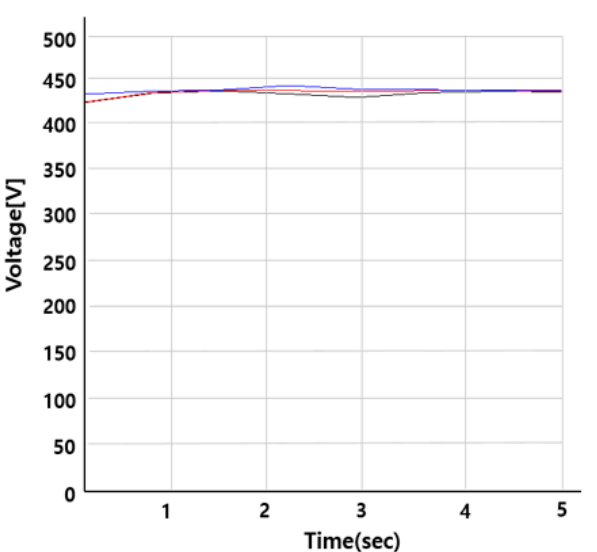

(h) $1800(\mathrm{rpm}), 443(\mathrm{~V})$

$\square$ Phase A Phase B $\square$ Phase C

Figure 16. Output results of the reference voltage with respect to the generator speed.(a) output voltage at $1100 \mathrm{rpm},(\mathbf{b})$ output voltage at $1200 \mathrm{rpm}$, (c) output voltage at $1300 \mathrm{rpm},(\mathbf{d})$ output voltage at $1400 \mathrm{rpm}$, (e) output voltage at $1500 \mathrm{rpm}$, (f) output voltage at $1600 \mathrm{rpm}$, (g) output voltage at $1700 \mathrm{rpm}$, and (h) output voltage at $1800 \mathrm{rpm}$. 
As a result of analyzing the operation mode of the ship, it could be classified into normal seagoing (without reefer; with reefer), port in/out (without thruster; with thruster), and load/unload. As for the load, the speed of the generator was changed according to the load change from $125 \mathrm{~kW}$ to $357 \mathrm{Kw}$, and it was confirmed that the output voltage normally follows the target value. Figure 17a shows the generator speed according to the load change, and Figure $17 \mathrm{~b}$ presents the generator output voltage according to the load change.

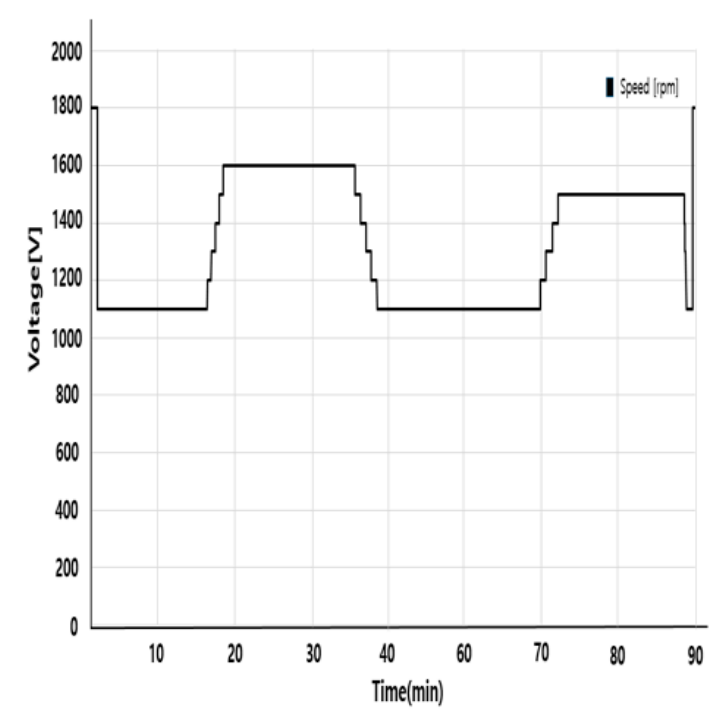

(a)

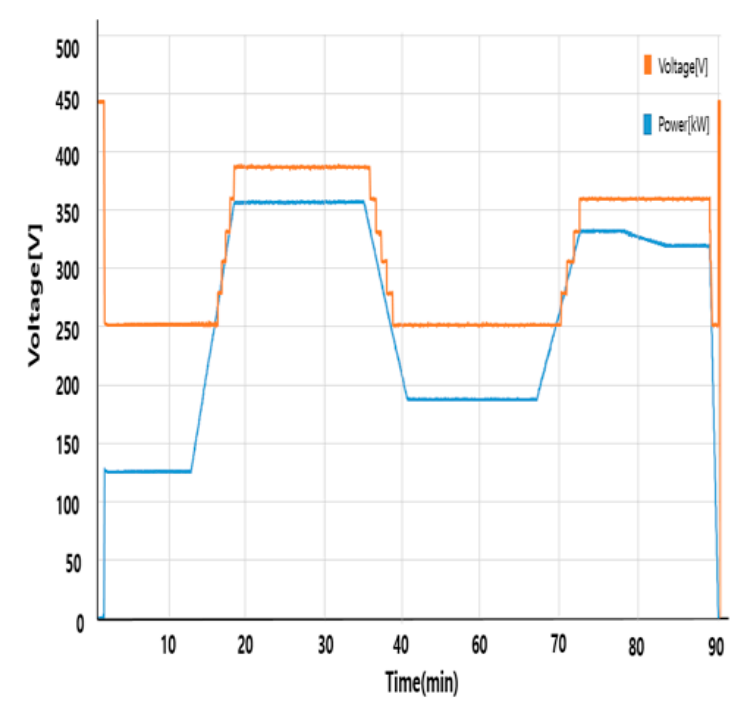

(b)

Figure 17. (a) The result of speed to load variation, (b) voltage according to load variation.

\section{Discussion}

Most of the studies conducted on DC distribution systems were focused on the enhancement of the energy efficiency and reduction of emissions due to the decrease in the fuel consumption, when compared with AC distribution systems in ships. However, in this study, a reference voltage control method suitable for speed fluctuations was applied using a neural network controller, to prevent damage to the internal windings of the generator due to the excessive magnetic flux and overexcitation that may occur during the variable-speed operation of the synchronous generator installed in the DC distribution system.

In this study, an experiment was conducted by configuring a variable speed synchronous power generation engine system on a testbed, thus simulating an environment similar to that of an actual electric propulsion ship. With the variations in speed suggested as the aim of the initial study, significant results were obtained in which the voltage output from the synchronous generator applied to the neural network controller was adjusted. The results suggest that safety can be ensured when the synchronous generator in variable-speed operation is implemented in the DC distribution system of a ship.

However, the scope of the current research is limited to the generator reference voltage control, and not the power system, which includes the entire power source from the propulsion motor to the propulsion motor. Although the findings of this study are significant, the application of the proposed method is limited, given that the power system of an electric propulsion ships is not only composed of a power source. In future work, research will be conducted on an integrated power management system that can control and manage the entire power system of a DC grid electric propulsion ship, for application to actual ships, which can serve as a useful guideline. 


\section{Conclusions}

In this study, a neural network controller was employed as the control unit of the power management system to change the reference voltage of the variable speed synchronous generator engine and to stably maintain the changed voltage. The neural network controller controls the input current of the potentiometer, which adjusts the size of the variable resistance supplied to the external input resistance, to change the reference voltage of the automatic voltage regulator with respect changes in the speed.

Based on the experimental results, the following conclusions can be reached.

(1) A synchronous power generation system installed on an actual testbed was used to determine the input/output patterns for the training of a neural network, and a current of 4-20 mA was supplied to the input of the potentiometer, to output the variable resistance value for the setting of the reference voltage matched with respect to the rotational speed of the generator. In addition, the output variable resistance value was inputted into the external resistance terminal of the automatic voltage regulator, and the actual generator output voltage was measured by operating the synchronous generator on the testbed.

(2) The neural network was trained using the measured input/output pattern, and the neural network controller applied with the optimal connection weight obtained through the training process was mounted in the control unit of the power management system.

(3) The operation range of the variable speed of the synchronous generator was set as 1100-1800 rpm, and the input current of the potentiometer calculated by the neural network controller was outputted with respect to an increase/decrease in the speed in intervals of $100 \mathrm{rpm}$. The potentiometer then outputted a variable resistance, and the output variable resistance was inputted into the reference voltage control circuit of the automatic voltage regulator. The experimental results confirmed that the reference voltage of the generator was adjusted with respect to the speed. In addition, upon the input of an arbitrary speed command that was not previously used for neural network training, an appropriate reference voltage was outputted through the calculation of the neural network controller.

Author Contributions: Conceptualization, H.J. and J.K.; methodology, H.J. and J.K.; software, H.J.; validation, H.J. and J.K.; formal analysis, H.J.; investigation, H.J. and J.K.; writing —original draft preparation, H.J.; writing-review and editing, H.J. and J.K.; visualization, H.J.; supervision, J.K.; project administration, J.K.; funding acquisition, J.K. All authors have read and agreed to the published version of the manuscript.

Funding: This research was funded by the Korea Institute of Marine Science \& Technology Promotion (KIMST), grant number 20180066.

Acknowledgments: The authors would like to express our gratitude to Kyoungkuk Yoon, Seongwan Kim and MASTC (Marine Application Subtantiation Technology Center at Korea Maritime and Ocean Univ. for their the kindest support.

Conflicts of Interest: The authors declare no conflict of interest.

\section{References}

1. National Air Pollutants Emission Information Center. National Air Pollutants Emission Service. Available online: https://airemiss.nier.go.kr/mbshome/mbs/airemiss/index.do (accessed on 5 June 2020).

2. Lee, T.; Nam, H. A study on green shipping in major countries: In the view of shipyards, shipping companies, ports, and policies. Asian J. Shipp. Logist. 2017, 33, 253-262. [CrossRef]

3. IMO. Fourth IMO Greenhouse Gas Study 2020. Available online: http://asq.kr/n8ptzWc9z1ce! (accessed on 23 September 2020).

4. KMI. Trend Analysis Report. Available online: http://bitly.kr/b73lIU2jbPY (accessed on 24 May 2020).

5. KMI. A Study on Assessment and Certification System for Reduction Technology of Emission from Ships; KMI: Busan, Korea, 2019.

6. MOTIE. Laying the Legal Basis for Expanding the Development and Distribution of Eco-Friendly Ships. Available online: http://bitly.kr/Up78GmWPmyaU (accessed on 3 July 2020). 
7. Clarksons Research. Reearch's World Fleet Register. Available online: http://asq.kr/VzUZAmVkV1HB (accessed on 15 June 2020).

8. Jeon, H.; Kim, J.; Yoon, K.-K. Large-scale electric propulsion systems in ships using an active front-end rectifier. J. Mar. Sci. Eng. 2019, 7, 168. [CrossRef]

9. Market Research Report. Electric Ships Market by Power Source, Autonomy, Ship Type and Region-Global Forecast to 2030. Available online: http://asq.kr/WM1G9LIRDimX (accessed on 11 June 2020).

10. Machowski, J.; Robak, S.; Bialek, J.W.; Bumby, J.R.; Abi-Samra, N. Decentralized stability-enhancing control of synchronous generator. IEEE Trans. Power Syst. 2000, 15, 1336-1344. [CrossRef]

11. Luo, L.; Gao, L.; Fu, H. The control and modeling of diesel generator set in electric propulsion ship. Int. J. Inf. Technol. Comput. Sci. 2011, 3, 31-37. [CrossRef]

12. Anbarasi, S.; Muralidharan, S. Enhancing the transient performances and stability of AVR system with BFOA tuned PID controller. J. Control Eng. Appl. Inform. 2016, 18, 20-29.

13. Bhatt, V.K.; Bhongade, S. Design of PID controller in automatic voltage regulator (AVR) system using PSO technique. Int. J. Eng. Res. Appl. 2013, 3, 1480-1485.

14. Gaing, Z.-L. A particle swarm optimization approach for optimum design of PID controller in AVR system. IEEE Trans. Energy Convers. 2004, 19, 384-391. [CrossRef]

15. Mosaad, A.M.; Attia, M.A.; Abdelaziz, A.Y. Whale optimization algorithm to tune PID and PIDA controllers on AVR system. Ain Shams Eng. J. 2019, 10, 755-767. [CrossRef]

16. Zamani, M.; Karimi-Ghartemani, M.; Sadati, N.; Parniani, M. Design of a fractional order PID controller for an AVR using particle swarm optimization. Control Eng. Pract. 2009, 17, 1380-1387. [CrossRef]

17. Sedaghati, A. A PI controller based on gain-scheduling for synchronous generator. Turk. J. Electr. Eng. Comput. Sci. 2006, 14, 241-251.

18. Kim, K.; Rao, P.; Burnworth, J.A. Self-tuning of the PID controller for a digital excitation control system. IEEE Trans. Ind. Appl. 2010, 46, 1518-1524. [CrossRef]

19. Çelik, E. Incorporation of stochastic fractal search algorithm into efficient design of PID controller for an automatic voltage regulator system. Neural Comput. Appl. 2018, 30, 1991-2002. [CrossRef]

20. Al Gizi, A.J.; Mustafa, M.; Al Zaidi, K.M.; Al-Zaidi, M.K. Integrated PLC-fuzzy PID Simulink implemented AVR system. Int. J. Electr. Power Energy Syst. 2015, 69, 313-326. [CrossRef]

21. Shao, L.; Gao, Y.; Shao, X.; Ou, Q.; Zhang, S.; Liu, Q.; Zhang, B.; Wu, J.; Ruan, Q.; Shen, L.; et al. CTLA-4 blockade reverses the Foxp3+ T-regulatory-cell suppression of anti-tuberculosis T-cell effector responses. In Proceedings of the Application of self-tuning fuzzy PID controller on the AVR system. In Proceedings of the 2012 IEEE International Conference on Mechatronics and Automation, Chengdu, China, 5-8 August 2012; Cold Spring Harbor Laboratory: New York, NY, USA, 2020; pp. 2510-2514.

22. Mukherjee, V.; Ghoshal, S. Comparison of intelligent fuzzy based AGC coordinated PID controlled and PSS controlled AVR system. Int. J. Electr. Power Energy Syst. 2007, 29, 679-689. [CrossRef]

23. Vasanthi, S.; Gopila, M.; Gnanambal, I. Fuzzy and PID excitation control system with AVR in power system stability analysis. Int. J. Eng. Adv. Technol. 2012, 2249-8958.

24. Ansari, J.A.; Shah, M.A. Probabilistic feedforward neural network based power system stabilizer for excitation control system of synchronous generator. Bahria Univ. J. Inf. Commun. Technol. 2015, 8, 70-74.

25. Bhutto, A.A.; Chachar, F.A.; Hussain, M.; Bhutto, D.K.; Bakhsh, S.E. Implementation of probabilistic neural network (PNN) based automatic voltage regulator (AVR) for excitation control system in Matlab. In Proceedings of the 2019 2nd International Conference on Computing, Mathematics and Engineering Technologies (iCoMET), Sukkur, Pakistan, 30-31 January 2019; Institute of Electrical and Electronics Engineers (IEEE): New York, NY, USA, 2019; pp. 1-5.

26. Memon, A.P.; Memon, A.S.; Akhund, A.A.; Memon, R.H. Multilayer perceptrons neural network automatic voltage regulator with applicability and improvement in power system transient stability. Int. J. Emerg. Trends Electr. Electron. 2013, 9, 30-38.

27. Senjyu, T.; Fujita, H. Recurrent neural network supplementary stabilization controller for automatic voltage regulator and governor. Electr. Power Components Syst. 2003, 31, 693-707. [CrossRef]

28. Hansen, J.F.; Wendt, F.; Lindtjørn, J.O. In Fuel-efficient power plant featuring variable speed generation system for DP drilling units. In Proceedings of the Dynamic Positioning Conference, Houston, TX, USA, 11-12 October 2016; pp. 1-13. 
29. Miyazaki, M.R.; Sorensen, A.J.; Vartdal, B.J. Reduction of fuel consumption on hybrid marine power plants by strategic loading with energy storage devices. IEEE Power Energy Technol. Syst. J. 2016, 3, 207-217. [CrossRef]

30. Yuan, L.C.W.; Tjahjowidodo, T.; Lee, G.S.G.; Chan, R.; Ådnanes, A.K. In Equivalent consumption minimization strategy for hybrid all-electric tugboats to optimize fuel savings. In Proceedings of the 2016 American Control Conference (ACC), Boston, MA, USA, 6-8 July 2016; pp. 6803-6808.

31. De Jong, W.; Robinson, J. Generator failures caused by synchronising torques. Inst. Mar. Eng. Trans. 1986, $99,8$.

32. Gross, L.C.; Anderson, L.S.; Young, R.C. Avoid Generator and System Damage Due to a Slow Synchronizing Breaker; Wisconsin Electric Power Company and Schweitzer Engineering Laboratories: Pullman, WA, USA, 1997.

33. Oh, S.J.; Kim, H.S.; Kim, S.H. A Study on the Transient Phenomenon Analysis at the instant of Parallel Running for AC Generators. J. Korean Soc. Mar. Eng. 2001, 25, 1065-1075.

34. Oh, S.-G.; Kim, J.-S.; Kim, S.-H.; Lee, S.-G.; Jo, S.-K. A Study on the transient phenomenon analysis of ship generator synchronization. J. Korean Soc. Mar. Eng. 2007, 31, 998-1004. [CrossRef]

35. Kim, K.; Park, K.; Roh, G.; Chun, K. DC-grid system for ships: A study of benefits and technical considerations. J. Int. Marit. Saf. Environ. Aff. Shipp. 2018, 2, 1-12. [CrossRef]

36. Hansen, J.F.; Wendt, F. History and state of the art in commercial electric ship propulsion, integrated power systems, and future trends. Proc. IEEE 2015, 103, 2229-2242. [CrossRef]

37. Tufte, E.D. Impacts of Low Load Operation of Modern Four-Stroke Diesel Engines in Generator Configuration. Master's Thesis, NTNU, Trondheim, Norway, 2014.

38. Kozak, M. In New concept of ship's power plant system with varying rotational speed gensets. In Proceedings of the 58th International Conference of Machine Design Departments, Prague, Czech Republic, 6-8 September 2017; pp. 170-175.

39. Mozina, C.J. Lessons Learned From Generator Tripping Events. IEEE Ind. Appl. Mag. 2010, 16, 29-36. [CrossRef]

40. Alves, E.F.; De Souza, M.A. Analysis of overexcitation relaying set up in synchronous generators for hydro power plants. In Proceedings of the 2008 IEEE/PES Transmission and Distribution Conference and Exposition, Bogota, Columbia, 13-15 August 2008; Institute of Electrical and Electronics Engineers (IEEE): New York, NY, USA, 2010; pp. 298-303.

41. Sasic, M. Deterioration Processes in Large Generator Stator Cores. Available online: http://asq.kr/ PaHRjslKazH (accessed on 2 July 2020).

42. Hasani, A.; Haghjoo, F; Da Silva, F.F.; Bak, C.L. Loss of field protection of synchronous generator in a realistic framework using RTDS. In Proceedings of the 2018 IEEE International Conference on Environment and Electrical Engineering and 2018 IEEE Industrial and Commercial Power Systems Europe (EEEIC/I\&CPS Europe), Palrmo, Italy, 12-15 June 2018; pp. 1-5.

43. Planas, E.; Andreu, J.; Gárate, J.I.; De Alegría, I.M.; Ibarra, E. AC and DC technology in microgrids: A review. Renew. Sustain. Energy Rev. 2015, 43, 726-749. [CrossRef]

44. Prenc, R.; Cuculić, A.; Baumgartner, I. Advantages of using a DC power system on board ship. J. Marit. Transp. Sci. 2016, 52, 83-97. [CrossRef]

45. Baran, M.; Mahajan, N. DC distribution for industrial systems: Opportunities and challenges. IEEE Trans. Ind. Appl. 2003, 39, 1596-1601. [CrossRef]

46. Castellan, S.; Menis, R.; Tessarolo, A.; Sulligoi, G. In Power electronics for all-electric ships with MVDC power distribution system: An overview. In Proceedings of the 2014 Ninth International Conference on Ecological Vehicles and Renewable Energies (EVER), Monte Carlo, Monaco, 25-27 March 2014; pp. 1-7.

47. Hammerstrom, D.J. In AC versus DC distribution systemsdid we get it right? In Proceedings of the 2007 IEEE Power Engineering Society General Meeting, Tampa, FL, USA, 24-28 June 2007; pp. 1-5.

48. Hansen, J.F.; Lindtjørn, J.O.; Vanska, K. In Onboard DC Grid for enhanced DP operation in ships. In Proceedings of the Dynamic Positioning Conference, Houston, TX, USA, 11-12 October 2011; pp. 1-8.

49. Syverud, T.H. Modeling and Control of a DC-Grid Hybrid Power System with Battery and Variable Speed Diesel Generators. Master's Thesis, NTNU, Trondheim, Norway, 2016.

50. Geertsma, R.; Negenborn, R.; Visser, K.; Hopman, J. Design and control of hybrid power and propulsion systems for smart ships: A review of developments. Appl. Energy 2017, 194, 30-54. [CrossRef]

51. ABB. ABB: Tests Confirm up to $27 \%$ Fuel Savings on Ships from Onboard DC Grid. Available online: http://asq.kr/uFww4mREiCMK (accessed on 8 May 2020). 
52. Mozina, C.J.; Reichard, M.; Bukhala, Z.; Conrad, S.; Crawley, T.; Gardell, J.; Hamilton, R.; Hasenwinkle, I.; Herbst, D.; Henriksen, L. In Coordination of generator protection with generator excitation control and generator capability. In Proceedings of the Conference Record of 2008 54th Annual Pulp and Paper Industry Technical Conference, Seattle, WA, USA, 22-27 June 2008; pp. 62-76.

53. Maughan, C.V. Generator Inspections, Failures. Combined Cycle J. 2011.

54. Demuth, H.B.; Beale, M.H.; De Jess, O.; Hagan, M.T. Neural Network Design, 2nd ed.; Campus Pub. Service, University of Colorado Bookstore: Boulder, CO, USA, 2002.

55. Haykin, S.S. Neural Networks and Learning Machines, 1st ed.; Prentice Hall: New York, NY, USA, 2009.

56. Hameed, A.A.; Karlik, B.; Salman, M.S. Back-propagation algorithm with variable adaptive momentum. Knowl.-Based Syst. 2016, 114, 79-87. [CrossRef]

57. Li, J.; Cheng, J.-H.; Shi, J.-Y.; Huang, F. Brief Introduction of Back Propagation (BP) Neural Network Algorithm and Its Improvement. Adv. Intell. Soft Comp. 2012, 2, 553-558. [CrossRef]

Publisher's Note: MDPI stays neutral with regard to jurisdictional claims in published maps and institutional affiliations.

(C) 2020 by the authors. Licensee MDPI, Basel, Switzerland. This article is an open access article distributed under the terms and conditions of the Creative Commons Attribution (CC BY) license (http://creativecommons.org/licenses/by/4.0/). 